
HYBRID CENSORED DATA

\author{
M.A.W. Mahmoud ${ }^{a}$, L.S. Diab ${ }^{b}$, M.G.M. Ghazal ${ }^{c}$, Baria.A.H ${ }^{\text {b }}$ \\ ${ }^{a}$ Department of Mathematics, Faculty of Sciences, Al-Azhar University, Cairo, Egypt. \\ ${ }^{b}$ Department of Mathematics, Faculty of Sciences, Al-Azhar University, Girls Branch, Cairo, Egypt. \\ ${ }^{c}$ Department of Mathematics, Faculty of Sciences, Minia University, El-Minia, Egypt.
}

\begin{abstract}
In this article, we will study the estimation of the unknown parameters for exponentiated gamma distribution as well as a survival function, failure rate function and the coefficient of variation based on unified hybrid censored data. In addition that, we will study maximum likelihood and Bayesian estimates. To calculate the Bayes estimates of the model parameters will beused Markov chain Monte Carlo method (MCMC). Gibbs within the Metropolis-Hasting algorithm has been applied to generate MCMC samples from the posterior density function and calculate approximate confidence intervals for the unknown parameters, survival, failure rate functions and coefficient of variation. All resultsobtained are based on the balanced-squared error loss, balanced linear-exponential loss, and balanced general entropy loss functions. At the end of article, real data has been used to determine how the estimation method can be used in practice.
\end{abstract}

Keywords: Exponentiated gamma distribution, Unified hybrid censored data, Bayesian estimation, MCMC method.

\title{
1 - INTRODUCTION
}

The gamma distribution is the most popular model for studying skewed data. Gupta et al.[1] presented the exponentiated gamma (EG) distribution. For more details, see Bakoban[2] and Shawky and Bakoban[3]. The EG distribution has the cumulative distribution function (cdf):

$$
\mathrm{F}(\mathrm{x}, \theta, \gamma)=\left(1-(1+\gamma \mathrm{x}) \mathrm{e}^{-\gamma \mathrm{x}}\right)^{\theta}{ }^{\theta}
$$

Therefore, EG distribution has the probability density function (pdf):

$$
\mathrm{f}(\mathrm{x}, \theta, \gamma)=\theta \gamma^{2} \mathrm{x} e^{-\gamma x}\left[1-(1+\gamma \mathrm{x}) \mathrm{e}^{-\gamma \mathrm{x}}\right]^{\theta-1},
$$

where $\theta, \gamma, \boldsymbol{x}>0, \theta$ is the shape parameter and $Y$ is the scale parameter.

The survival function $(\mathrm{SF})$ or $\mathrm{S}(\mathrm{t})$ is given by

$$
\mathrm{S}(\mathrm{t})=1-\left(1-(1+\gamma \mathrm{t}) \mathrm{e}^{-\gamma \mathrm{t}}\right)^{\theta}{ }_{{ }} \quad \mathrm{t}>0 .
$$

The failure rate function $\mathrm{h}(\mathrm{t})$ is given by

$$
\boldsymbol{h}(\mathrm{t})=\frac{\theta \gamma^{2} \mathrm{te}^{-\gamma t}\left[1-(1+\gamma \mathrm{t}) \mathrm{e}^{-\gamma t}\right]^{\theta-1}}{1-\left(1-(1+\gamma \mathrm{t}) \mathrm{e}^{-\gamma t}\right)^{\theta}} .
$$

The coefficient of variation (CV) is used in many areas of science such as biology, economics, chemistry, psychology, and in engineering in reliability theory. The CV Based on the EG distribution $(\theta, \gamma)$ is given by

$$
\mathrm{C} . \mathrm{V}=\frac{\sigma_{\mathrm{x}}}{\mathrm{E}(\mathrm{X})}
$$


where $\sigma_{\mathrm{x}}=\sqrt{E\left(\mathrm{X}^{2}\right)-[\mathrm{E}(\mathrm{X})]^{2}}$ is the standard deviation of $\mathrm{X}$, where $\mathrm{E}(\mathrm{X})$ and $\mathrm{E}\left(\mathrm{X}^{2}\right)$ are the first and the second moments of the EG distribution $(\theta, \gamma)$, can be obtained by using binomial theorem and the definition of gamma function we have

$$
\begin{aligned}
& \mathrm{E}\left(\mathrm{X}^{s}\right)=\theta \gamma^{2} \int_{0}^{\infty}\left[\boldsymbol{x}^{s+1} e^{-\gamma x}\left[1-(1+\gamma \mathrm{X}) \mathrm{e}^{-\gamma x}\right]^{(\theta-1)} d x_{s} \quad \theta \geq 1,\right. \\
& =\theta \gamma^{2} \sum_{\mathrm{q}=0}^{m} \mathrm{E}(-1)^{\mathrm{q}}\left(\begin{array}{c}
\theta-1 \\
\mathrm{q}
\end{array}\right) \int_{0}^{m \infty} \mathrm{x}^{s+1} \mathrm{e}^{-(\mathrm{q}+1) \mathrm{rx}}(1+\gamma \mathrm{x})^{\mathrm{q}} d x
\end{aligned}
$$

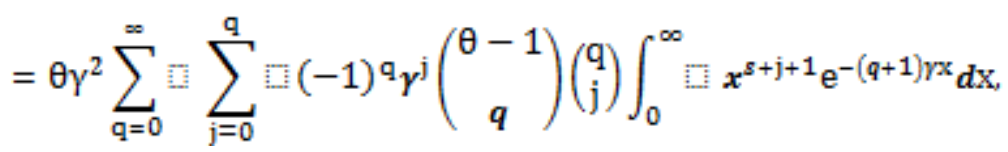

$$
\begin{aligned}
& =\frac{\theta}{\gamma^{8}} \sum_{q=0}^{\infty} \sum_{j=0}^{q} \frac{(-1)^{q}\left(\begin{array}{c}
\theta-1 \\
q
\end{array}\right)\left(\begin{array}{l}
q \\
j
\end{array}\right)(\Gamma(s+j+2))}{(1+q)^{s+j+2}} .
\end{aligned}
$$

A sample is supposed to be censored if out of $n$ items placed on a life test, only $(m<n)$ of them are essentially detected to fail. So there are several different censoring schemas as follows. Assume $n$ identical items are located on a life-testing experiment. Suppose that their lifetimes are independent and identically distributed from EG distribution. Let the ordered failure times of these items be denoted by $\mathrm{X}_{1: n}, \mathrm{X}_{2 \mathrm{n}, \ldots}, \mathrm{X}_{\mathrm{nnn}}$. Epstein[4] considered a hybrid censored scheme (HCS), which is a combination of Type-I and Type-II censoring schemes. In Type-I HCS, the life-testing experiment is finished at a random time $\mathrm{T}_{1}^{*}=\min \left(\boldsymbol{x}_{\mathrm{r}: \mathrm{n}}, \mathrm{T}\right)$, where $\mathbf{1} \leq \boldsymbol{r} \leq \boldsymbol{n}$ and $\mathrm{T} \in(0, \infty)$ are fixed. The disadvantage of Type-I HCS is very few failures occurring until the pre-fixed time $\mathrm{T}_{1}^{*}$. To overcome this disadvantage, Childs et al.[5] proposed a new HCS, referred to as Type-II hybrid censoring scheme (Type-II HCS), which guarantees fixed number of failures. In this case, the termination time of the experiment is $\mathrm{T}_{2}^{*}=\max \left(\boldsymbol{x}_{\mathrm{r} \cdot \mathrm{n}}, \mathrm{T}\right)$, where $\mathbf{1} \leq \boldsymbol{r} \leq \boldsymbol{n}$ and $\mathrm{T} \in(0, \infty)$ are fixed. Although the Type-II HCS guarantees a specified number of failures, it has the disadvantage that it might take a very long time to observe $r$ failures and complete the life-test. Chandrasekar et al.[6] improved these schemes of censored sampling by introducing two extensions of this type, named as generalized TypeI HCS and generalized Type-II HCS. In generalized Type-I HCS, one fixes $\mathrm{k}, \mathrm{r} \in(1,2, \ldots, \mathrm{n})$ and time $\mathrm{T} \in(0, \infty)$ where $\mathrm{k}<\mathrm{r}<\boldsymbol{n}$. If the $\mathrm{k}^{\mathrm{th}}$ failure happens before time $\mathrm{T}$, the termination time of the experiment is $\mathrm{T}^{*}=\min \left(\mathrm{x}_{\operatorname{rin}}, T\right)$. If the $\mathrm{k}^{\text {th }}$ failure happens after time $\mathrm{T}$, the termination time in this case is $x_{k n n}$, see Saieed F. Ateya[7]. In generalized Type-II HCS, one fixes $r \in(1,2, \ldots, n)$ and $\mathrm{T}_{1}, \mathrm{~T}_{2} \in(0, \infty)$ s.t $\mathrm{T}_{1}<\mathrm{T}_{2}$. If the $\mathrm{r}^{\text {th }}$ failure happens before time $\mathrm{T}_{1}$, the termination time of the experiment is $\mathrm{T}_{1}$; if the $\mathrm{r}^{\text {th }}$ failure happened between $\mathrm{T}_{1}$ and $\mathrm{T}_{2}$, the the termination time in this case is $X_{r i n}$; otherwise, the experiment is finished at $T_{2}$. Though these two new schemes of censored sampling are improvements over the old ones, they still face some problems. For example, in the generalized Type-I HCS, because of only one pre-assigned time T, we cannot guarantee $r$ failures. In the generalized Type-II HCS, there is a possibility of not observing any failure at all or observe very few failures until the pre-fixed time $\mathrm{T}_{2}$, and so it has the problem as the Type-I HCS. To avoid the drawbacks in these schemes, Balakrishnan et al.[8] introduced a mixture of generalized Type-I HCS and generalized Type-II HCS and named the unified hybrid censoring scheme (UHCS), which can be described as follows, fix integers $\mathrm{r}_{v} \mathrm{k} \in \mathbf{1}, 2, \ldots, \mathrm{n}$ where $\mathrm{k}<\mathrm{r}<n$ and time points $\mathrm{T}_{1}, \mathrm{~T}_{2} \in(0, \infty)$ where $\mathrm{T}_{1}<\mathrm{T}_{2}$. If the $\mathrm{k}^{\text {th }}$ failure happend before time $\mathrm{T}_{1}$, the termination time of the experiment is $\mathrm{T}^{*}=\min \left(\max \left(\mathrm{x}_{\mathrm{rnn},}, \mathrm{T}_{1}\right), \mathrm{T}_{2}\right)$. If the $\mathrm{k}^{\text {th }}$ failure occurs between $\mathrm{T}_{1}$ and $\mathrm{T}_{2}$, the termination time is $\mathrm{T}^{*}=\min \left(\mathrm{x}_{\mathrm{rnn}}, \mathrm{T}_{2}\right)$ and if the $\mathrm{k}^{\text {th }}$ failure occurs after time $\mathrm{T}_{2}$, the experiment is finished at . Under 
this censoring scheme, we can guarantee that the experiment would be finished at most in time $\mathrm{T}_{2}$ with at least $\mathrm{k}$ failures and if not, we can guarantee exactly $\mathrm{k}$ failures. Therefore, under this UHCS, we have the following six cases:

Case I: $0<\mathrm{x}_{\mathrm{kin}}<\mathrm{x}_{\mathrm{r}, \mathrm{n}}<\mathrm{T}_{1}<\mathrm{T}_{2}$ in this case $\mathrm{T}^{*}=\mathrm{T}_{1}$,

Case II: $0<\mathrm{x}_{\mathrm{knn}}<\mathrm{T}_{1}<x_{\mathrm{rnn}}<\mathrm{T}_{2}$ in this case $\mathrm{T}^{*}=\mathrm{x}_{\mathrm{rnn}}$,

Case III: $0<\mathrm{x}_{\mathrm{knn}}<\mathrm{T}_{1}<T_{2}<x_{\mathrm{r}: \mathrm{n}}$ in this case $\mathrm{T}^{*}=\mathrm{T}_{2}$,

Case IV: $0<\mathrm{T}_{1}<\mathrm{x}_{\mathrm{knn}}<x_{\mathrm{r}: \mathrm{n}}<\mathrm{T}_{2}$ in this case $\mathrm{T}^{*}=\mathrm{x}_{\mathrm{rnn}}$,

Case V: $0<\mathrm{T}_{1}<\mathrm{x}_{\mathrm{knn}}<T_{2}<x_{\mathrm{rn} n}$ in this case $\mathrm{T}^{*}=\mathrm{T}_{2}$,

Case VI: $0<\mathrm{T}_{1}<\mathrm{T}_{2}<\mathrm{x}_{\mathrm{knn}}<x_{\mathrm{rnn}}$ in this case $\mathrm{T}^{*}=\mathrm{x}_{\mathrm{knn}}$.

The article is organized as follows. In the next section, the maximum likelihood (ML) estimators of the unkown parameters. In section (3), asymptotic confidence intervals (CIs) based on ML estimator are obtained. In section (4), we will study Bayesian estimation based on balanced loss functions. MCMC for estimating the posterior distribution of the unkown parameters, survival function, failure rate function and CV in section (5). Finally, real data set has been analyzed in section (6), and conclusion is given in section (7).

\section{2 - Maximum likelihood estimation:}

In this section we derive the ML estimations of the unkown parameters of EG distribution, $\mathrm{S}(\mathrm{t})$, $h(t)$, and CV under UHCS as follows. Let $x_{1: n}, x_{2 i n}, \ldots, x_{D i n}$ be an UHCS observed from a life test involving $\mathrm{n}$ units taken from a population with $\mathrm{F}(\mathrm{x})$ and $\mathrm{f}(\mathrm{x})$ given in Equations (1) and (2), then the likelihood function of $\theta, \gamma$, for six cases is given by

$$
\mathrm{L}(\mathrm{x} ; \theta ; \gamma)=\frac{\mathrm{n!}}{(\mathrm{n}-\mathrm{D}) !\left[\Pi_{\mathrm{i}=1}^{\mathrm{D}} \Pi \mathrm{f}\left(\mathrm{x}_{\mathrm{i}}\right)\right][1-\mathrm{F}(\mathrm{c})]^{\mathrm{n}-\mathrm{D}}} .
$$

Where $\mathrm{D}$ represent number of failures up to time c. And is given by

$$
\text { (D, c) }=\left(\begin{array}{cc}
\left(\mathrm{d}_{1}, \mathrm{~T}_{1}\right) & \text { for I, } \\
\left(\mathrm{r}_{1} \mathrm{x}_{\mathrm{rnn}}\right) & \text { for II and IV, } \\
\left(\mathrm{d}_{2}, \mathrm{~T}_{2}\right) & \text { for III and V, } \\
\left(\mathrm{k}, \mathrm{x}_{\mathrm{knn}}\right) & \text { for VI. }
\end{array}\right.
$$

where $d_{1}$ and $d_{2}$ the number of failures that occur before $T_{1}$ and $T_{2}$, respectively. Then the likelihood function is given

$$
\begin{gathered}
\mathrm{L}(\underline{\mathrm{x}} ; \theta, \gamma)=\frac{\mathrm{n} !}{(\mathrm{n}-\mathrm{D}) !\left[\prod_{\mathrm{i}=1}^{\mathrm{D}} \boldsymbol{\mathrm { D }} \theta \mathrm{\gamma}^{2} \mathrm{x}_{\mathrm{i}} \mathrm{e}^{\left.-\gamma \mathrm{x}_{\mathrm{i}}\left[1-\left(1+\gamma \mathrm{x}_{\mathrm{i}}\right) \mathrm{e}^{\left.-\gamma x_{\mathrm{i}}\right]}\right]^{\theta-1}\right]}\right.} \\
{\left[1-\left(1-(1+\gamma \mathrm{c}) \mathrm{e}^{-\gamma \mathrm{c}}\right)^{\theta}\right]^{\mathrm{n}-\mathrm{D}} .}
\end{gathered}
$$

the estimation of the parameters $\theta$ and $Y$, can be obtained by taking the logarithm of (10) we get

$$
\begin{aligned}
& \mathrm{l}(\underline{\mathrm{x}}, \theta, \gamma)=\ln \mathrm{C}+\mathrm{D} \ln \theta+2 D \ln \gamma+\ln \sum_{\mathrm{i}=1}^{\mathrm{D}} x_{\mathrm{i}}-\gamma \sum_{i=1}^{\mathrm{D}} \mathrm{x}_{\mathrm{i}}+(\theta-1) \\
& \sum_{\mathrm{i}=1}^{D} \ln \left[1-\left(1+\gamma \mathrm{x}_{\mathrm{i}}\right) \mathrm{e}^{-\gamma \mathrm{x}_{\mathrm{i}}}\right]+(\mathrm{n}-\mathrm{D}) \ln \left[1-\left(1-(1+\gamma \mathrm{c}) \mathrm{e}^{-\gamma \mathrm{c}}\right)^{\theta}\right] \text {, } \\
& \text { where } \mathrm{K}=\frac{\mathrm{D} !}{(\mathrm{n}-\mathrm{D}) !} \text {. }
\end{aligned}
$$


Then differentiate (11) with respect to $\theta$ and $Y$ and solve the result equations as follows.

$$
\begin{aligned}
& \frac{\mathrm{D}}{\theta}+\sum_{\mathrm{i}=1}^{\mathrm{D}} \ln \left[1-\left(1+\gamma \mathrm{x}_{\mathrm{i}}\right) \mathrm{e}^{-\gamma \mathrm{x}_{\mathrm{i}}}\right] \\
& -\frac{(\mathrm{n}-\mathrm{D}) \ln \left[1-(1+\gamma \mathrm{c}) \mathrm{e}^{-\gamma \mathrm{c}}\right]\left[1-(1+\gamma \mathrm{c}) \mathrm{e}^{-\gamma \mathrm{c}}\right]^{\Theta}}{1-\left[1-(1+\gamma \mathrm{c}) \mathrm{e}^{-\gamma \mathrm{c}}\right]^{\theta}}=0 \text {, } \\
& \frac{2 \mathrm{D}}{\gamma}-\sum_{\mathrm{i}=1}^{\mathrm{D}} \mathbb{\mathrm { E }} \mathrm{x}_{\mathrm{i}}+(\theta-1) \sum_{\mathrm{i}=1}^{\mathrm{D}} \frac{\mathrm{\gamma x}_{\mathrm{i}}^{2} \mathrm{e}^{-\gamma \mathrm{x}_{\mathrm{i}}}}{1-\left(1+\gamma \mathrm{x}_{\mathrm{i}}\right) \mathrm{e}^{-\gamma \mathrm{x}_{\mathrm{i}}}} \\
& -\frac{\gamma \theta c^{2}(n-D) e^{-\gamma c}\left[1-(1+\gamma c) e^{-\gamma c}\right]^{(\theta-1)}}{1-\left[1-(1+\gamma c) e^{-\gamma c}\right]^{\theta}}=0 .
\end{aligned}
$$

There is no analytical solution for these equations in $\theta$ and $Y$ some numerical methods are used to get $\widehat{\gamma}_{M L}$ and $\widehat{\theta}_{M L}$. To find the value of ML estimators of $S(t), h(t)$ and $C V$ replace ${ }^{\theta}$ and $Y$ by $\hat{\gamma}_{M L}$ and $\widehat{\theta}_{\mathrm{ML}}$.

$\left(S_{-}^{\circ} M L(t)=1-\left(1-\left(1+\gamma_{-}^{\wedge} M L \mathrm{t}\right) e^{\wedge}\left(-\gamma_{-} M \mathrm{~L} t\right)\right)^{\wedge}\left(\theta_{-}^{\circ} M L\right), @ @ \mathrm{~h}_{-}^{-} M L(t)\right.$

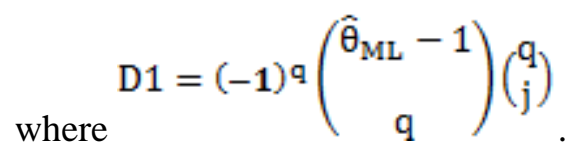

\section{3 - Bayesian estimation:}

In this section, we find Bayesian estimates of the unknown parameters $\theta$ and $Y$, in addition to $S(t), \boldsymbol{h}(t)$ and $\mathrm{CV}$ based on balanced-squared error loss (BSEL), balanced linear-exponential (BLINEX) loss, and the balanced general entropy(BGE) loss functions. We assume that $\theta$ and $Y$ are independently distribution as gamma $a_{1}, b_{1}$ and gamma $a_{2}, b_{2}$ priors, respectively. Then, the priors of $\theta$ and $Y$ are

$$
\begin{aligned}
& g_{1}(\theta) \propto\left(\theta^{a_{1}-1} e^{-b_{1} \theta}\right), \theta>0, \\
& g_{2}(\gamma) \propto\left(\gamma^{a_{2}-1} e^{-\gamma b_{2}}\right), \gamma>0 .
\end{aligned}
$$

where $a_{1}, a_{2}, b_{1}$ and $b_{2}>0$. The joint prior distribution for $\theta$ and $Y$ is

$$
g(\theta, \gamma) \propto \theta^{a_{1}-1} \gamma^{a_{2}-1} e^{-\left(b_{1} \theta+b_{2} \gamma\right)} .
$$

The posterior distribution is given by

$$
\mathrm{g}^{*}(\alpha \mid \underline{\mathrm{x}})=\frac{\mathrm{L}(\mathrm{x} \mid \alpha) g(\alpha)}{\mathrm{f}(\underline{\mathrm{x}})}=\frac{L(\underline{\mathrm{x}} \mid \alpha) \mathrm{g}(\alpha)}{\int \mathrm{L}(\underline{\mathrm{x}} \mid \alpha) g(\alpha)} .
$$

where $g(\alpha)$, is the prior distribution for the parameter, $L(x \mid \alpha)$, is the likelihood function, $f(x)$, is the marginal function and $\mathrm{g}^{*}(\alpha \mid \underline{\mathrm{x}})$, is the posterior distribution for the parameter.

From (15) and (16) we obtain the joint posterior density function as follows

$$
\begin{aligned}
& \mathrm{g}^{*}(\theta, \gamma \mid \underline{\mathrm{x}}) \quad \propto \theta^{\mathrm{D}+\mathrm{a}_{1}-1} \gamma^{\mathrm{a}_{2}+2 \mathrm{D}-1} \mathrm{e}^{-\gamma\left(\mathrm{b}_{2}+\sum_{\mathrm{i}=1}^{\mathrm{D}} \mathrm{Di}_{\mathrm{i}}\right)}
\end{aligned}
$$

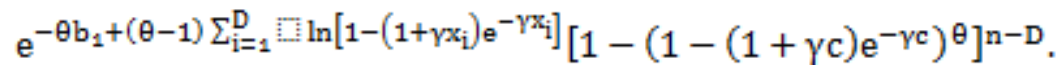


Note that is not possible to calculate (17) analytically because it very difficult to get clear forms for the marginal posterior distributions for each parameter. Then, we suggested method to approximate (17), this method is Markov Chain Monte Carlo.

See Jozani et al.[9] presented a generalized loss function called the balanced loss function of the form

$$
\mathrm{L}_{\rho, \omega, \xi o}(\phi, \rho)=\omega \rho(\xi, \xi 0)+(1-\omega) \rho(\phi, \xi) \text {. }
$$

where $\mathbf{0} \leq \boldsymbol{\omega} \leq \mathbf{1}, \rho$ is an arbitrary loss function and $\xi 0$ is a chosen prior estimator of $\phi$ and $\xi$ is an estimator. In BSEL loss function $\rho(\phi, \xi)=(\xi-\phi)^{2}$, then (18) take the form

$$
\mathrm{L}_{\rho, \omega, \xi o}=\omega(\xi-\xi o)^{2}+(1-\omega)(\xi-\phi)^{2}
$$

and the Bayes estimate in this case is

$$
\phi_{\mathrm{BS}}(\underline{\mathrm{x}})=\omega \xi \mathrm{O}+(1-\omega) \mathrm{E}(\phi \mid \underline{\mathrm{x}}) .
$$

If we choice

$$
\rho(\phi, \xi)=\mathrm{e}^{\mathrm{a}(\xi-\xi \circ)}-\mathrm{a}(\xi-\phi)-1,
$$

we will get the BLINEX loss function where $\mathbf{a} \neq \mathbf{0}$, and the Bayes estimate of $\phi$ in this case is, see Zellner[10]

$$
\phi_{\mathrm{BL}}(\underline{\mathrm{x}})=\frac{-1}{a} \ln \left[\omega \mathrm{e}^{-\mathrm{a} \xi \mathrm{o}}+(1-\omega) E\left(\mathrm{e}^{-\mathrm{a} \phi} \mid \underline{\mathrm{x}}\right)\right] .
$$

And if we choice

$$
\rho(\xi, \phi)=\left(\frac{\xi 0}{\phi}\right)^{-\alpha}-a \ln \left(\frac{\xi 0}{\phi}\right)-1,
$$

we will get the BGE loss function where $\mathrm{a} \neq \mathbf{0}$, and the Bayes estimate of $\phi$ in this case is

$$
\phi_{\mathrm{BG}}(\underline{\mathrm{x}})=\left[\omega(\xi \mathrm{o})^{-\mathrm{a}}+(1-\omega) \mathrm{E}\left(\phi^{-\mathrm{a}} \mid \underline{\mathrm{x}}\right)\right]^{\frac{-1}{\mathrm{a}}} .
$$

\section{4 - Confidence Interval}

Consider a life-testing experiment in which $\mathrm{n}$ similar units are located on a life-test. Let $\mathrm{x}_{1}<\mathrm{x}_{2}<\cdots<\mathrm{x}_{\mathrm{n}}$ denote the corresponding life-times from EG distribution. The Fisher information matrix $I(\theta, \gamma)$, is obtained by taking the expectation of minus of the second derivatives of the loglikelihood of the parameters $\theta$ and $Y$ given the vector of observations.

$$
\mathrm{I}_{\mathrm{ij}}=-E\left(\frac{\partial^{2} l}{\partial \phi_{\mathrm{i}} \partial \phi_{\mathrm{j}}}\right) ; \quad \mathrm{i}, \mathrm{j}=1,2, \phi_{\mathrm{i}}=\theta, \phi_{\mathrm{j}}=\gamma .
$$

Take the approximate asymptotic variance-covariance matrix for the ML estimators.

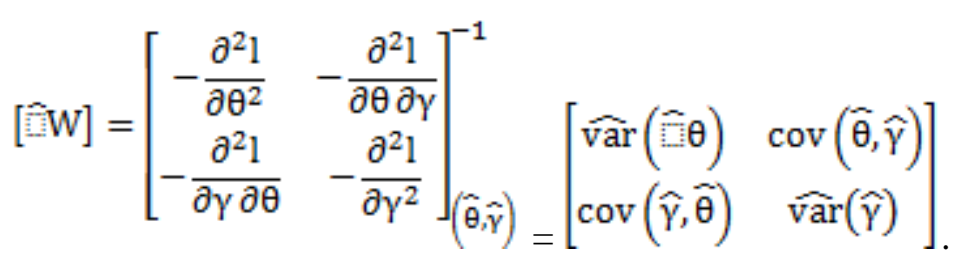

To calculate the approximate confidence intervals (ACI)s for $\theta$ and $Y$, we can use asymptotic normality of the ML estimators. Therefore, $(1-\lambda) 100 \%$ confidence intervals $(\mathrm{CI}) \mathrm{s}$ for parameters $\theta$ and $Y$ become 


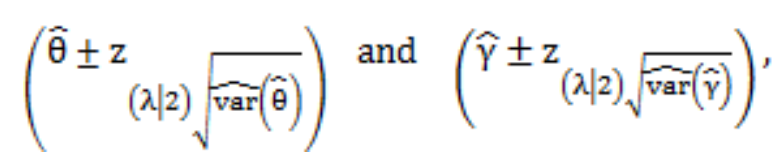

where $\mathrm{Z}_{(\lambda \mid 2)}$ is the percentile of the standard normal distribution with right-tail probability $\lambda{ }^{\lambda \mid 2}$.

To construct the asymptotic CIs of the $\mathrm{S}(\mathrm{t}), \mathrm{h}(\mathrm{t})$ and $\mathrm{CV}$, we need to find the variances of them, we use the delta method. According to this method, the variance of $\hat{\mathrm{S}}_{\mathrm{ML}}, \widehat{\mathrm{H}}_{\mathrm{ML}}$ and $\widehat{\mathrm{CV}}_{\mathrm{ML}}$, can be approximated, respectively by

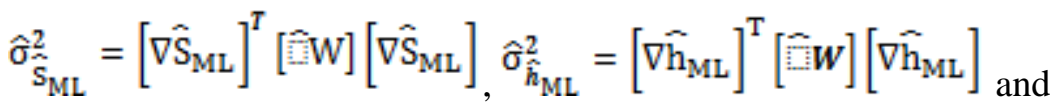

$$
\begin{aligned}
& \hat{\sigma}_{\widetilde{\mathrm{CV}}_{\mathrm{ML}}}^{2}=\left[\nabla \widehat{\nabla C V}_{\mathrm{ML}}\right]^{\mathrm{T}}[\hat{\mathrm{H}} \boldsymbol{W}]\left[\nabla \overline{\mathrm{C}} \widehat{\mathrm{V}}_{\mathrm{ML}}\right] \text {, }
\end{aligned}
$$

then, the $(1-\lambda) 100 \%$ two sided CIs of $\theta, Y, S(t), h(t)$ and $C V$, can be written as

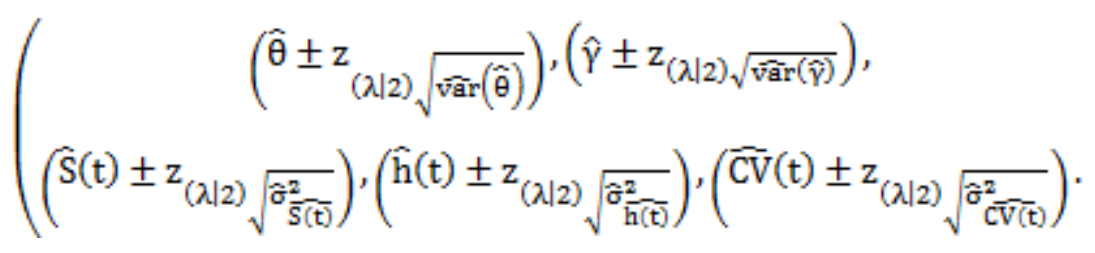

where $\overrightarrow{\nabla \mathrm{S}} \widehat{\mathrm{ML}}, \widehat{\nabla \mathrm{h}}_{\mathrm{ML}}$ and $\widehat{\nabla C V}_{\mathrm{ML}}$ are the gradient of $\widehat{\mathrm{S}}_{\mathrm{ML}}, \widehat{\mathrm{h}}_{\mathrm{ML}}$ and $\widehat{\mathrm{CV}}_{\mathrm{ML}}$ with respect to $\theta$ and $Y$.

\section{5 - MCMC Method}

Equation (17) is complicated and no closed form inferences appear possible. So, we use the MCMC method, see Chen and Shao[11]. To generate samples from the posterior distributions this samples can be drawn and then compute the Bayes estimates of $\theta$ and $Y$ in addition to $S(t), h(t)$ and $\mathrm{CV}$ and also to construct associated Cls.

From (17), the posterior density function of $Y$ given $\theta$ is

$$
g_{1}^{*}(\gamma \mid \theta, \underline{x})=\gamma^{a_{2}+D-1} e^{-\gamma\left(b_{2}+\Sigma_{i=1}^{D} D x_{i}\right)} .
$$

Similary, the full posterior conditional distribution for $\theta$ is

$$
\begin{gathered}
g_{2}^{*}(\theta \mid \gamma, \underline{x})=\gamma^{D} \theta^{D+a_{1}-1} e^{-\theta b_{1}+(\theta-1) \sum_{i=1}^{D} \mathbb{E} \ln \left[1-\left(1+\gamma x_{i}\right) e^{-\gamma x_{i}}\right]} \\
{\left[1-\left[1-(1+\gamma c) e^{-\gamma c}\right]^{\theta}\right]^{n-D} .}
\end{gathered}
$$

It can be seen that $\mathrm{g}_{1}^{*}(\gamma \mid \theta, \underline{\mathrm{x}})$ is a gamma density with shape parameter $\left(\mathrm{D}+\mathrm{a}_{2}\right)$ and scale parameter $\left(\mathrm{b}_{2}+\sum_{\mathrm{i}=1}^{\mathrm{D}} \mathrm{x}_{\mathrm{i}}\right)$.

. Also, $g_{2}^{*}(\theta \mid \gamma, \underline{x})$ cannot be reduced analytically to well known distributions so we can not take sample directly by standard methods, and therefore we use the Metropolis-Hastings method with normal proposal distribution. MCMC algorithm used in this article to calculate the Bayesian estimate of $Y$ and ${ }^{\theta}, \mathrm{S}(\mathrm{t}), \mathrm{h}(\mathrm{t})$ and $\mathrm{CV}$ and find the corresponding CIs. Also, used to draw samples from the posterior density functions(17)

\section{Algorithm}


1) Start with initial $\left(\theta^{(0)}{ }_{\circ}^{(0)}\right)$, N=burn-in.

2) $\operatorname{Set} l=1$.

3) Generate $\gamma^{(\mathbb{I})}$ from Gamma $\left(\mathrm{D}+\boldsymbol{a} \_\mathbf{2}, \boldsymbol{b} \_2+\Sigma(i=1)^{\wedge} \mathrm{D} \equiv \boldsymbol{x}_{-} \mathbf{i}\right)$.

4) Using Metropolis-Hastings, see Metropolis et al.[12] generate $\theta^{(1)}$ from $g_{2}^{*}(\theta \mid \gamma, \underline{x})$ with the $\mathrm{N}\left(\theta^{(1-1)}{ }_{,} \sigma^{2}\right)$ proposal distribution. where $\sigma^{2}$ is the variance of $Y$ obtained using variance-covariance matrix.

5) Compute $\mathrm{S}(\mathrm{t}), \mathrm{h}(\mathrm{t})$ and $\mathrm{CV}$ as

$$
\begin{aligned}
& s^{(1)}(t)=1-\left(1-\left(1+\gamma^{(1)} t\right) e^{-\gamma^{(1)} t}\right)^{\theta^{(1)}} .
\end{aligned}
$$

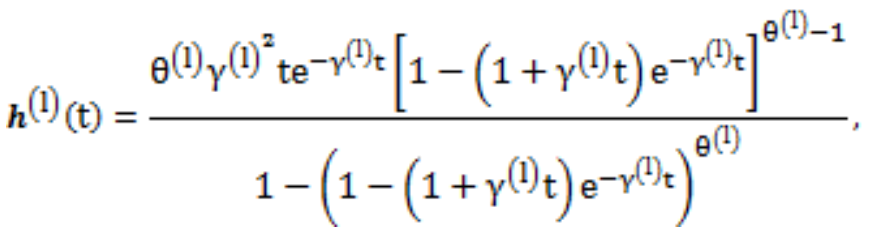

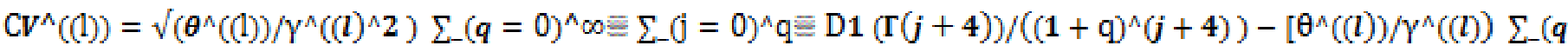

$$
\text { where }^{\mathrm{D} 1=(-\mathbf{1})^{\mathrm{q}}}\left(\begin{array}{c}
\theta^{(1)}-1 \\
\mathrm{q}
\end{array}\right)\left(\begin{array}{l}
q_{j} \\
\mathrm{j}
\end{array}\right)
$$

6) $\operatorname{Set} 1=1+1$.

7) Repeat steps $(3-6) \mathrm{N}$ times.

8) By arranging $\gamma^{(\mathrm{l})}, \theta^{(\mathrm{l})}, \mathrm{S}^{(\mathrm{l})}(\mathrm{t}), \boldsymbol{h}^{(\mathrm{l})}(\mathrm{t})$, and $\mathrm{CV}^{(\mathrm{l})}, \mathrm{l}=\mathrm{M}+\mathbf{1}, \ldots, \mathrm{N}$ in ascending orders, the approximate $(1-\gamma) 100 \%$ CIs for $\phi=\gamma, \theta, \mathrm{S}(\mathrm{t}), \mathrm{h}(\mathrm{t})$ or $\mathrm{CV}$ is

$$
\left(\phi^{\frac{\mathrm{N}-\mathrm{M}) \tau}{2}}, \phi\left((\mathrm{N}-\mathrm{M})\left(1-\frac{\tau}{2}\right)\right)\right)
$$

Then the approximate Bayes estimates of $\phi=\gamma, \theta, \mathrm{S}(\mathrm{t}), \mathrm{h}(\mathrm{t})$ and CV based on BSEL, BLINEX and BGE loss functions

$$
\begin{gathered}
\widehat{\phi}_{\mathrm{BS}}=\omega \widehat{\phi}_{\mathrm{ML}}+\frac{1-\omega}{\mathrm{N}-\mathrm{M}} \sum_{\mathrm{l}=\mathrm{M}+1}^{\mathrm{N}} \overline{\mathrm{E}} \phi^{(\mathrm{l})}, \\
\widehat{\phi}_{\mathrm{BL}}=\frac{-1}{\mathrm{a}} \ln \left[\omega \mathrm{e}^{-\mathrm{a} \widehat{\phi}_{\mathrm{ML}}}+\frac{1-\omega}{\mathrm{N}-\mathrm{M}} \sum_{\mathrm{l}=\mathrm{M}+1}^{\mathrm{N}} \mathrm{E} \mathrm{e}^{-\mathrm{a} \phi^{(\mathrm{l})}}\right], \\
\widehat{\phi}_{\mathrm{BG}}=\left[\omega\left(\hat{\phi}_{\mathrm{ML}}\right)^{-\mathrm{a}}+\frac{1-\omega}{\mathrm{N}-\mathrm{M}} \sum_{\mathrm{l}=\mathrm{M}+1}^{\mathrm{N}} \overline{\mathrm{I}}\left(\phi^{(1)}\right)^{-\mathrm{a}}\right]^{\frac{-1}{\mathrm{a}}} .
\end{gathered}
$$

\section{6 - Application to real life data}

A real data set is taken from Kumar and Umesh[13], these data represent the average monthly rainfall obtained from the Information System for Management of Water Resources from the State of 
So Paulo, including a period of 56 years from 1947 to 2003, for the month of November., which is represented as;

Table 1: real data set.

\begin{tabular}{llllllllllllll}
\hline 0.2 & 0.8 & 1.1 & 1.3 & 1.4 & 1.7 & 1.8 & 1.9 & 2.1 & 2.1 & 2.2 & 2.5 & 2.6 & 2.8 \\
2.8 & 2.9 & 2.9 & 2.9 & 2.9 & 3.1 & 3.2 & 3.3 & 3.5 & 3.5 & 3.5 & 3.7 & 3.8 & 3.8 \\
3.9 & 4 & 4.1 & 4.1 & 4.6 & 4.7 & 4.8 & 5 & 5.2 & 5.2 & 5.4 & 5.4 & 5.4 & 5.4 \\
5.5 & 5.5 & 6.2 & 6.2 & 6.7 & 6.9 & 7.3 & 7.3 & 7.4 & 8.7 & 8.8 & 9.9 & 10.8 & 24.1 \\
\hline
\end{tabular}

We plot the empirical SF and the fitted SF in the Fig[1] they show thatEG distribution ${ }^{\theta}, Y$ ) provide a reasonable fit to the above real data.

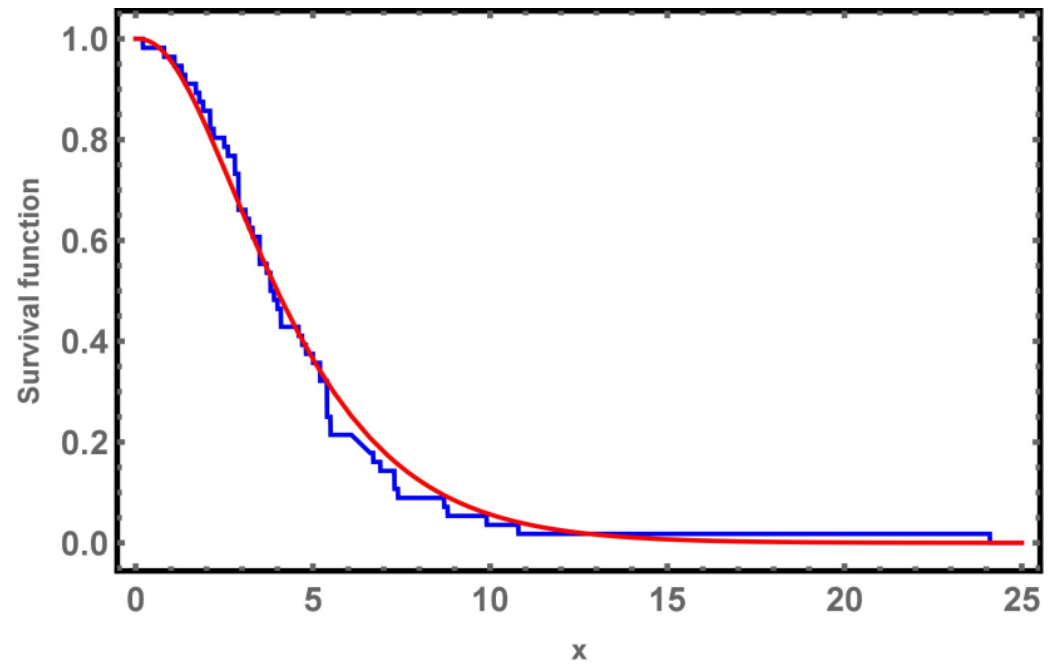

Figure 1: The empirical and fitted survival functions.

Now, we consider the case when the data are censored. We generate six UHCD sets from the uncensored data set as

Case I: $\mathrm{T} 1=8, \mathrm{~T} 2=10, \mathrm{k}=40, r=45$ in this case $\mathrm{D}=51, \mathrm{c}=\boldsymbol{T} 1=8$.

Case II:T1 $=5.6, \mathrm{~T} 2=10, \mathrm{k}=40, \mathrm{r}=45$ in this case $\mathrm{D}=45, \mathrm{c}=\mathrm{x}_{\mathrm{r}, \mathrm{n}}=6.2$.

Case III:T1 $=5,8, \mathrm{~T} 2=7, \mathrm{k}=40, r=50$ in this case $\mathrm{D}=48, \mathrm{c}=T 2=7$.

Case IV:T1 $=4, \mathrm{~T} 2=6.7, \mathrm{k}=35, r=47$ in this case $\mathrm{D}=47, \mathrm{c}=\mathrm{x}_{\mathrm{r}, \mathrm{n}}=6.7$.

Case V:T1 $=2, \mathrm{~T} 2=3, \mathrm{k}=15, r=25$ in this case $\mathrm{D}=19, \mathrm{c}=T 2=3$.

Case VI:T1 $=2, \mathrm{~T} 2=3, \mathrm{k}=25, r=30$ in this case $\mathrm{D}=25, \mathrm{c}=\mathrm{x}_{\mathrm{knn}}=3.5$.

In these cases, we used ML and Bayesian estimation to estimate the parameters $\gamma, \theta$ in addition to $\mathrm{S}(\mathrm{t}), \mathrm{h}(\mathrm{t})$ and $\mathrm{CV}$. We used MCMC where $\mathrm{M}=11000 \mathrm{MCMC}$ sample and $\mathrm{N}=1000$ values as "burn-in". used non-informative gamma priors for $Y$ and $\theta$ when $\left(a_{1}=a_{2}=b_{1}=b_{2}=0\right)$.

We computed the $95 \%$ ACIs based on the MCMC samples in Table (2). In Table (3) represent some characteristics of $\gamma, \theta$ in addition to $\mathrm{S}(\mathrm{t}), \mathrm{h}(\mathrm{t})$ and $\mathrm{CV}$. Also, we can determine the values of $\gamma, \theta, S(\mathrm{t}=0.4), \mathrm{h}(\mathrm{t}=0.4)$, and $\mathrm{CV}$, based on the three types of balanced loss functions with various value of a and $\omega$, result are given in Table (4). The histogram of $\gamma, \theta_{s} S(t), \mathrm{h}(t)$ and $\mathrm{CV}$ are displayed in Fig[2]. Also, plot the MCMC output of $\gamma, \theta, s(t), h(t)$, and CV in Fig[3]. 


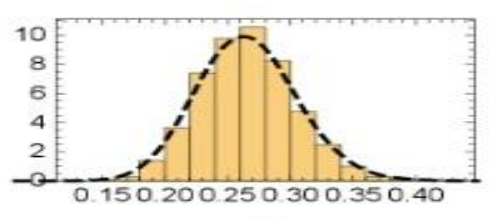

$\boldsymbol{\beta}$
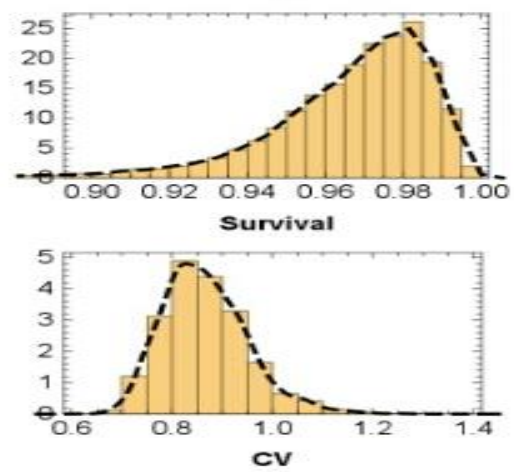
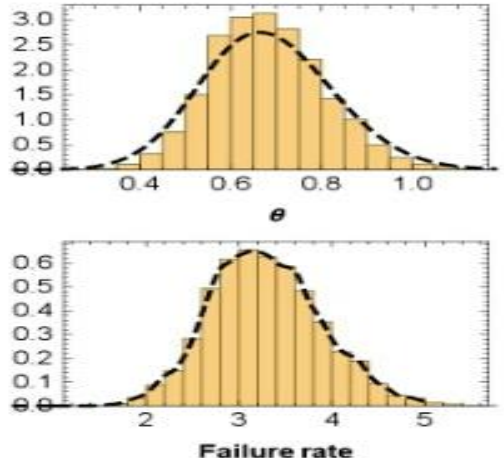

Figure 2: Histogram of $\gamma, \theta, s(\mathrm{t}), \mathrm{h}(\mathrm{t})$ and $\mathrm{CV}$ generated by MCMC method for case I.

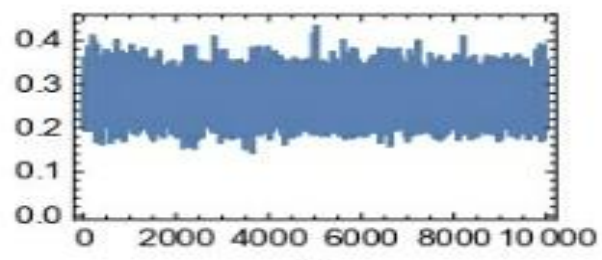

$\beta$

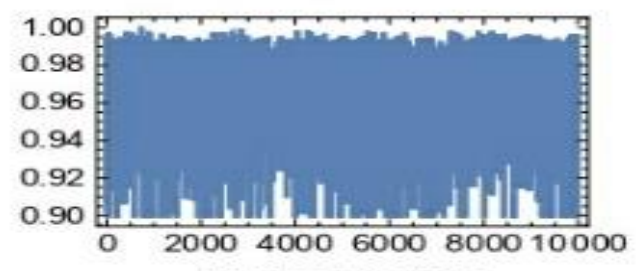

Survivalfunction

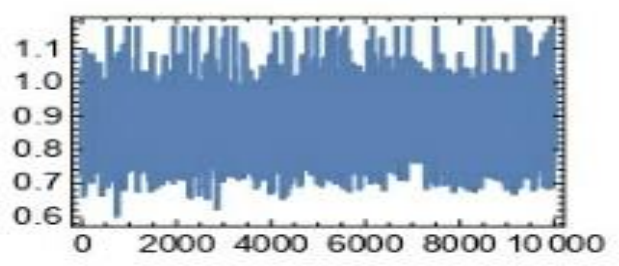

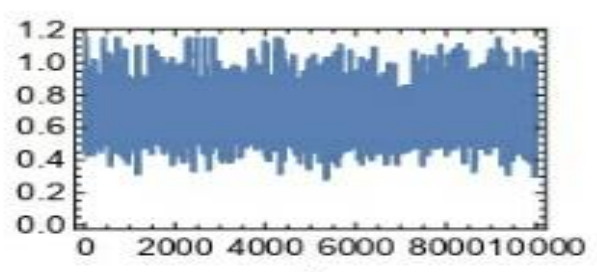

$\boldsymbol{\theta}$

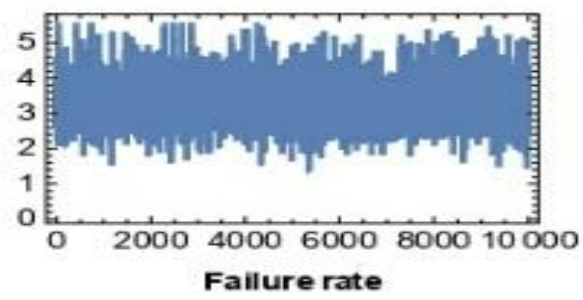

Figure 3: Simulation number of $\gamma_{s} \theta, S(\mathrm{t}), \mathrm{h}(\mathrm{t})$ and $\mathrm{CV}$ generated by MCMC method based on balanced loss function for Case I with non-informative priors.

It is clear this Figure for $\gamma, \theta, h(\mathrm{t})$ and $\mathrm{CV}$ have a long tail to the right, then they are said to be skewed to the right and have positive skewnes but, $\mathrm{S}(\mathrm{t})$ have a long tail to the left, then they are said to be skewed to the left and have negative skewnes. 
Table 2: The $95 \%$ confidence interval of ML estimates and MCMC for $\gamma, \boldsymbol{\theta}, \boldsymbol{S}, \boldsymbol{h}$ and CV for six cases of UHCS based on the observed Fisher information matrix.

\begin{tabular}{|c|c|c|c|c|c|c|c|}
\hline \multirow[b]{2}{*}{ Cases } & \multirow[b]{2}{*}{ Par } & \multirow[b]{2}{*}{ Lower } & \multirow{2}{*}{$\begin{array}{l}\text { MLE } \\
\text { Upper }\end{array}$} & \multirow[b]{2}{*}{ Length } & \multirow[b]{2}{*}{ Lower } & \multirow{2}{*}{$\begin{array}{c}\text { MCMC } \\
\text { Upper }\end{array}$} & \multirow[b]{2}{*}{ Length } \\
\hline & & & & & & & \\
\hline \multirow{5}{*}{ Case I } & $\gamma$ & 0.39982 & 0.6845 & 0.28468 & 0.19619 & 0.34299 & 0.14683 \\
\hline & $\Theta$ & 0.83958 & 2.05042 & 1.21084 & 0.45913 & 0.96291 & 0.50378 \\
\hline & $\mathrm{S}$ & 0.9897 & 1.0031 & 0.0134 & 0.91159 & 0.9934 & 0.08184 \\
\hline & $\mathrm{h}$ & 4.00183 & 9.42279 & 5.42095 & 2.21697 & 4.6295 & 2.4125 \\
\hline & $\mathrm{CV}$ & 0.50876 & 0.70434 & 0.19558 & 0.7194 & 1.0536 & 0.3341 \\
\hline \multirow{5}{*}{ Case II } & $\gamma$ & 0.38006 & 0.68152 & 0.30146 & 0.21177 & 0.38315 & 0.17138 \\
\hline & $\Theta$ & 0.79624 & 2.02224 & 1.226 & 0.48616 & 1.05026 & 0.5641 \\
\hline & $\mathrm{S}$ & 0.98875 & 1.00341 & 0.01466 & 0.91769 & 0.99502 & 0.07733 \\
\hline & $\mathrm{h}$ & 3.81221 & 9.30072 & 5.48851 & 2.34653 & 5.02775 & 2.68122 \\
\hline & $\mathrm{CV}$ & 0.509 & 0.71591 & 0.20691 & 0.69175 & 1.02118 & 0.32943 \\
\hline \multirow{5}{*}{ Case III } & $\gamma$ & 0.38927 & 0.67925 & 0.28999 & 0.20466 & 0.35889 & 0.15423 \\
\hline & $\Theta$ & 0.8164 & 2.02353 & 1.20713 & 0.47825 & 1.00463 & 0.52638 \\
\hline & $S$ & 0.98909 & 1.00327 & 0.01418 & 0.91975 & 0.99442 & 0.07467 \\
\hline & $\mathrm{h}$ & 3.89941 & 9.30702 & 5.40761 & 2.31154 & 4.83319 & 2.52165 \\
\hline & $\mathrm{CV}$ & 0.51014 & 0.71117 & 0.20103 & 0.70563 & 1.03036 & 0.32473 \\
\hline \multirow{5}{*}{ Case IV } & $Y$ & 0.3844 & 0.6774 & 0.2930 & 0.2063 & 0.3645 & 0.1581 \\
\hline & $\Theta$ & 0.8059 & 2.0133 & 1.2073 & 0.4905 & 1.0167 & 0.5262 \\
\hline & $\mathrm{S}$ & 0.9888 & 1.0033 & 0.01452 & 0.9224 & 0.9946 & 0.0722 \\
\hline & $\mathrm{h}$ & 3.8535 & 9.263 & 5.4095 & 2.3648 & 4.8803 & 2.5155 \\
\hline & $\mathrm{CV}$ & 0.5105 & 0.7142 & 0.2036 & 0.7018 & 1.0162 & 0.3144 \\
\hline \multirow{5}{*}{ Case V } & $Y$ & 0.23002 & 0.7521 & 0.5221 & 0.29725 & 0.7229 & 0.4256 \\
\hline & $\Theta$ & 0.5219 & 2.0629 & 1.5409 & 0.77714 & 1.9367 & 1.1595 \\
\hline & S & 0.9841 & 1.0055 & 0.0214 & 0.9596 & 0.99969 & 0.04003 \\
\hline & $\mathrm{h}$ & 2.6338 & 9.4581 & 6.8243 & 3.64663 & 9.0134 & 5.3668 \\
\hline & $\mathrm{CV}$ & 0.4817 & 0.7857 & 0.3093 & 0.54413 & 0.7975 & 0.2533 \\
\hline \multirow{5}{*}{ Case VI } & $\gamma$ & 0.28522 & 0.72379 & 0.43857 & 0.27302 & 0.60084 & 0.32782 \\
\hline & $\Theta$ & 0.61335 & 2.04885 & 1.4355 & 0.71181 & 1.64676 & 0.93495 \\
\hline & $S$ & 0.9858 & 1.0048 & 0.019 & 0.95765 & 0.9993 & 0.04165 \\
\hline & $\mathrm{h}$ & 3.02603 & 9.40482 & 6.3788 & 3.36758 & 7.73641 & 4.36883 \\
\hline & $\mathrm{CV}$ & 0.49217 & 0.76049 & 0.26832 & 0.57738 & 0.83375 & 0.25636 \\
\hline
\end{tabular}

Table 3: The characteristics for $\theta, Y, S, \boldsymbol{h}$ and CV for six cases of UHCS with non informative prior.

\begin{tabular}{llllllll}
\hline Cases & Par & Mean & Median & Mode & SD & MS & Ske \\
\hline \multirow{5}{*}{ Case I } & $\gamma$ & 0.2648 & 0.2632 & 0.2599 & 0.0372 & 0.2675 & 0.2709 \\
& $\Theta$ & 0.6878 & 0.6807 & 0.6686 & 0.1299 & 0.6989 & 0.4568 \\
& $\mathrm{~S}$ & 0.9672 & 0.9722 & 0.983 & 0.022 & 0.9671 & -1.7871 \\
& $\mathrm{~h}$ & 3.318 & 3.285 & 3.2324 & 0.6234 & 3.3708 & 0.4494 \\
& $\mathrm{CV}$ & 0.8623 & 0.8532 & 0.833 & 0.0865 & 0.8676 & 0.6634 \\
\hline \multirow{6}{*}{ Case II } & $\gamma$ & 0.2914 & 0.2889 & 0.2839 & 0.0435 & 0.2947 & 0.3359 \\
& $\Theta$ & 0.7535 & 0.745 & 0.7279 & 0.1423 & 0.7668 & 0.2913 \\
& $\mathrm{~S}$ & 0.9724 & 0.9776 & 0.9878 & 0.0204 & 0.9727 & -2.3654 \\
& $\mathrm{~h}$ & 3.6217 & 3.587 & 3.5177 & 0.6792 & 3.6848 & 0.2831 \\
& $\mathrm{CV}$ & 0.8236 & 0.8146 & 0.7967 & 0.0832 & 0.8278 & 0.9485 \\
\hline \multirow{5}{*}{ Case III } & $\gamma$ & 0.2754 & 0.273 & 0.2683 & 0.0394 & 0.2782 & 0.3244 \\
& $\Theta$ & 0.7144 & 0.7066 & 0.6909 & 0.1321 & 0.7265 & 0.4369 \\
& $\mathrm{~S}$ & 0.9698 & 0.9744 & 0.9836 & 0.0198 & 0.97 & -1.7132 \\
& $\mathrm{~h}$ & 3.4415 & 3.4061 & 3.3353 & 0.6321 & 3.499 & 0.4289 \\
& $\mathrm{CV}$ & 0.8452 & 0.8369 & 0.8202 & 0.0819 & 0.8492 & 0.6563 \\
\hline \multirow{6}{*}{ Case IV } & $\mathrm{S}$ & 0.2804 & 0.278 & 0.275 & 0.0409 & 0.2834 & 0.2705
\end{tabular}




\begin{tabular}{llllllll} 
& $\mathrm{h}$ & 3.4981 & 3.4484 & 3.3489 & 0.6515 & 3.5583 & 0.5176 \\
& $\mathrm{CV}$ & 0.8381 & 0.8311 & 0.817 & 0.081 & 0.842 & 0.5713 \\
\hline \multirow{4}{*}{ Case V } & $\gamma$ & 0.4874 & 0.4803 & 0.466 & 0.11 & 0.4996 & 0.4542 \\
& $\Theta$ & 1.3005 & 1.2744 & 1.2221 & 0.2987 & 1.3342 & 0.4308 \\
& $\mathrm{~S}$ & 0.9905 & 0.9948 & 1.002 & 0.0112 & 0.9912 & -3.7747 \\
& $\mathrm{~h}$ & 6.0822 & 5.9558 & 5.711 & 1.3747 & 6.2356 & 0.4201 \\
& $\mathrm{CV}$ & 0.645 & 0.6374 & 0.622 & 0.0647 & 0.6483 & 0.9491 \\
\hline \multirow{5}{*}{ Case VI } & $\gamma$ & 0.4224 & 0.4168 & 0.4057 & 0.0839 & 0.4307 & 0.3651 \\
& $\Theta$ & 1.1374 & 1.1222 & 1.0918 & 0.2496 & 1.1645 & 0.4215 \\
& $\mathrm{~S}$ & 0.9886 & 0.9925 & 1.0001 & 0.0132 & 0.9887 & -4.2001 \\
& $\mathrm{~h}$ & 5.3681 & 5.2968 & 5.1541 & 1.1643 & 5.492 & 0.4129 \\
& $\mathrm{CV}$ & 0.6806 & 0.6719 & 0.6545 & 0.0651 & 0.6837 & 0.874 \\
\hline
\end{tabular}

Table 4: Estimation of $\gamma, \theta, S, h$ and CV for MCMC method for six cases of UHCS with non informative prior.

\begin{tabular}{|c|c|c|c|c|c|c|c|c|c|c|}
\hline \multirow[b]{2}{*}{ Cases } & \multirow[b]{2}{*}{ Par } & \multirow[b]{2}{*}{ MLE } & \multirow[b]{2}{*}{$\omega$} & \multirow[b]{2}{*}{ BSEL } & \multirow[b]{2}{*}{$\mathbf{a}_{1}=-3$} & \multirow{2}{*}{$\begin{array}{l}\text { BLINEX } \\
a_{2}=0.25\end{array}$} & \multirow[b]{2}{*}{$a_{3}=10$} & \multirow[b]{2}{*}{$a_{1}=-3$} & \multirow{2}{*}{$\begin{array}{c}\text { BGE } \\
a_{2}=0.25\end{array}$} & \multirow[b]{2}{*}{$a_{3}=10$} \\
\hline & & & & & & & & & & \\
\hline \multirow{20}{*}{ Case I } & \multirow[t]{4}{*}{$\gamma$} & 0.54216 & 0.2 & 0.32028 & 0.34307 & 0.31861 & 0.27894 & 0.3624 & 0.2995 & 0.24027 \\
\hline & & & 0.4 & 0.3757 & 0.40513 & 0.37341 & 0.3035 & 0.42285 & 0.34459 & 0.24939 \\
\hline & & & 0.6 & 0.43122 & 0.45732 & 0.42887 & 0.34134 & 0.46955 & 0.39853 & 0.30406 \\
\hline & & & 1 & 0.54216 & 0.54216 & 0.54216 & 0.54216 & 0.54216 & 0.54216 & 0.54216 \\
\hline & \multirow[t]{4}{*}{$\Theta$} & 1.445 & 0.2 & 0.83835 & 1.03161 & 0.82536 & 0.63659 & 0.96254 & 0.77335 & 0.78268 \\
\hline & & & 0.4 & 0.99001 & 1.19119 & 0.97151 & 0.66521 & 1.12482 & 0.89614 & 0.91074 \\
\hline & & & 0.6 & 1.14167 & 1.29866 & 1.1232 & 0.0705 & 1.25029 & 1.0443 & 1.06098 \\
\hline & & & 1 & 1.445 & 1.445 & 1.445 & 1.445 & 1.445 & 1.445 & 1.445 \\
\hline & \multirow[t]{4}{*}{ S } & 0.9964 & 0.2 & 0.97276 & 0.9734 & 0.97258 & 0.9693 & 0.97317 & 0.97231 & 0.97236 \\
\hline & & & 0.4 & 0.97867 & 0.9793 & 0.97852 & 0.9757 & 0.97908 & 0.97826 & 0.97831 \\
\hline & & & 0.6 & 0.98458 & 0.9851 & 0.98447 & 0.9821 & 0.98492 & 0.98426 & 0.9843 \\
\hline & & & 1 & 0.9964 & 0.9964 & 0.9964 & 0.9964 & 0.9964 & 0.9964 & 0.9964 \\
\hline & \multirow[t]{4}{*}{ h } & 6.71231 & 0.2 & 3.99256 & 6.17639 & 3.75417 & 2.1754 & 4.52761 & 3.70727 & 3.74866 \\
\hline & & & 0.4 & 4.672 & 6.40709 & 4.31428 & 2.20411 & 5.25619 & 4.2659 & 4.3295 \\
\hline & & & 0.6 & 5.35244 & 6.54219 & 4.9671 & 2.24476 & 5.82473 & 4.9356 & 5.00556 \\
\hline & & & 1 & 6.71231 & 6.71231 & 6.71231 & 6.71231 & 6.71231 & 6.71231 & 6.71231 \\
\hline & \multirow[t]{4}{*}{$\mathrm{CV}$} & 0.60655 & 0.2 & 0.81194 & 0.83613 & 0.80987 & 0.73225 & 0.83163 & 0.79858 & 0.74006 \\
\hline & & & 0.4 & 0.76059 & 0.79183 & 0.7580 & 0.68347 & 0.78685 & 0.7441 & 0.66454 \\
\hline & & & 0.6 & 0.70924 & 0.74072 & 0.70692 & 0.65083 & 0.73629 & 0.69433 & 0.63034 \\
\hline & & & 1 & 0.60655 & 0.60655 & 0.60655 & 0.60655 & 0.60655 & 0.60655 & 0.60655 \\
\hline \multirow{12}{*}{$\begin{array}{l}\text { Case } \\
\text { II }\end{array}$} & \multirow[t]{4}{*}{$\gamma$} & 0.53079 & 0.2 & 0.33857 & 0.35623 & 0.33725 & 0.30205 & 0.3704 & 0.32183 & 0.26228 \\
\hline & & & 0.4 & 0.38663 & 0.40915 & 0.38476 & 0.32749 & 0.42265 & 0.36262 & 0.26992 \\
\hline & & & 0.6 & 0.43468 & 0.45481 & 0.43285 & 0.3617 & 0.46444 & 0.41009 & 0.28108 \\
\hline & & & 1 & 0.53079 & 0.53079 & 0.53079 & 0.53079 & 0.53079 & 0.53079 & 0.53079 \\
\hline & \multirow[t]{4}{*}{$\Theta$} & 1.40924 & 0.2 & 0.88835 & 1.0347 & 0.87804 & 0.69031 & 0.98184 & 0.83605 & 0.605 \\
\hline & & & 0.4 & 1.01857 & 1.17405 & 1.00438 & 0.71905 & 1.12123 & 0.94668 & 0.62265 \\
\hline & & & 0.6 & 1.1488 & 1.27202 & 1.13483 & 0.75955 & 1.23258 & 1.07624 & 0.64841 \\
\hline & & & 1 & 1.40924 & 1.40924 & 1.40924 & 1.40924 & 1.40924 & 1.40924 & 1.40924 \\
\hline & \multirow[t]{4}{*}{$S$} & 0.99608 & 0.2 & 0.97779 & 0.97834 & 0.97774 & 0.9756 & 0.97817 & 0.97754 & 0.97522 \\
\hline & & & 0.4 & 0.98236 & 0.98286 & 0.98232 & 0.98034 & 0.98271 & 0.98213 & 0.98 \\
\hline & & & 0.6 & 0.98693 & 0.98733 & 0.9869 & 0.98532 & 0.98721 & 0.98675 & 0.98505 \\
\hline & & & 1 & 0.99608 & 0.99608 & 0.99608 & 0.99608 & 0.99608 & 0.99608 & 0.99608 \\
\hline
\end{tabular}


M.A.W. MAHMOUD, et al

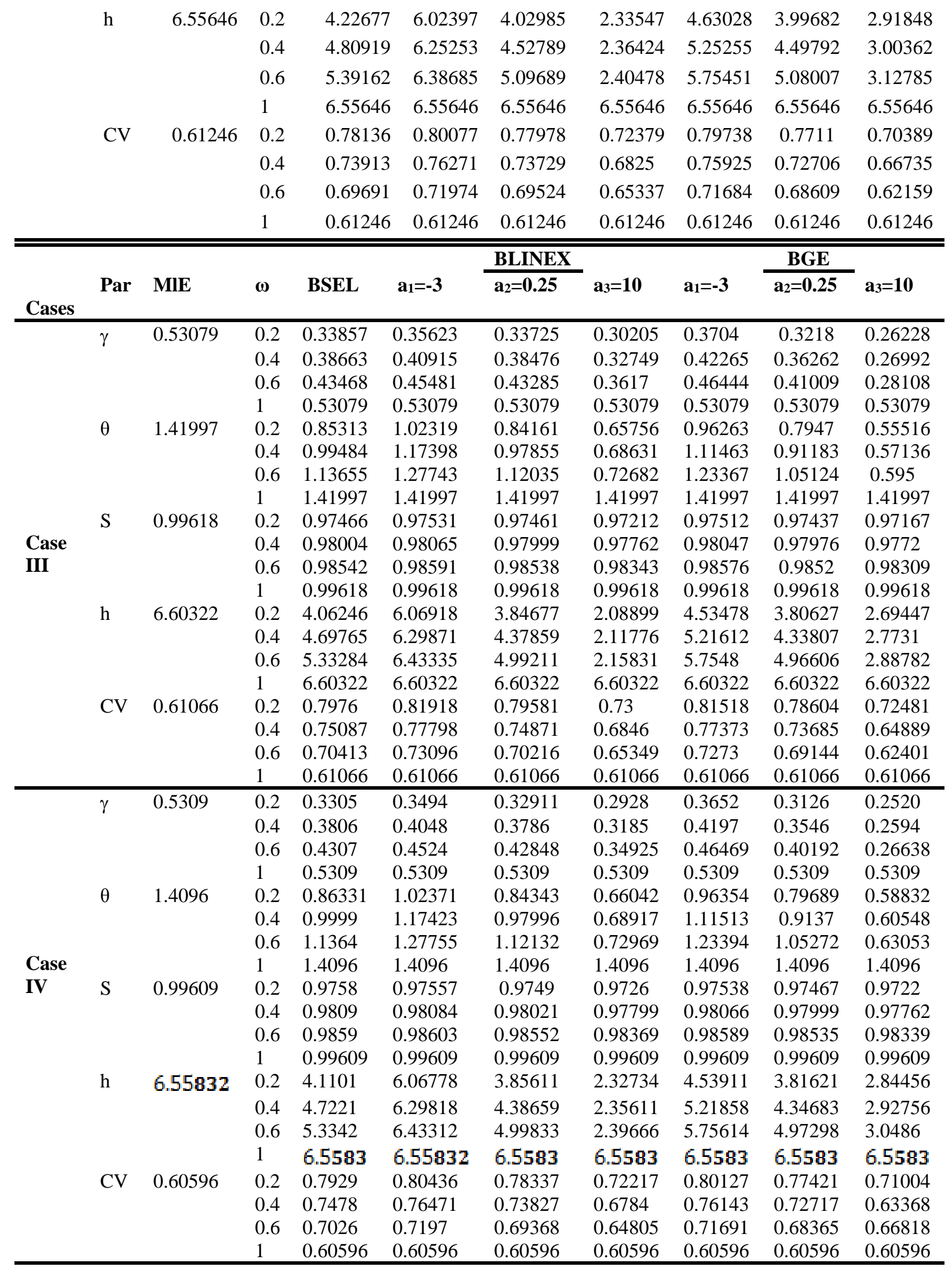


Continue Table (4)

\begin{tabular}{|c|c|c|c|c|c|c|c|c|c|c|}
\hline \multirow[b]{2}{*}{ Cases } & \multirow[b]{2}{*}{ Par } & \multirow[b]{2}{*}{ MIE } & \multirow[b]{2}{*}{$\omega$} & \multirow[b]{2}{*}{ BSEL } & \multirow[b]{2}{*}{$a_{1}=-3$} & \multirow{2}{*}{$\begin{array}{l}\text { BLINEX } \\
a_{2}=0.25 \\
\end{array}$} & \multirow[b]{2}{*}{$a_{3}=10$} & \multirow[b]{2}{*}{$a_{1}=-3$} & \multirow{2}{*}{$\begin{array}{r}\text { BGE } \\
a_{2}=0.25 \\
\end{array}$} & \multirow[b]{2}{*}{$a_{3}=10$} \\
\hline & & & & & & & & & & \\
\hline \multirow{20}{*}{ Case V } & \multirow[t]{4}{*}{$\gamma$} & 0.46407 & 0.2 & 0.47427 & 0.48834 & 0.47317 & 0.43429 & 0.49288 & 0.46261 & 0.32822 \\
\hline & & & 0.4 & 0.47172 & 0.48244 & 0.47089 & 0.44094 & 0.486 & 0.46297 & 0.33744 \\
\hline & & & 0.6 & 0.46917 & 0.47643 & 0.46861 & 0.44807 & 0.47891 & 0.46334 & 0.35069 \\
\hline & & & 1 & 0.46407 & 0.46407 & 0.46407 & 0.46407 & 0.46407 & 0.46407 & 0.46407 \\
\hline & \multirow[t]{4}{*}{$\theta$} & 1.23507 & 0.2 & 1.27973 & 1.40017 & 1.27148 & 1.00807 & 1.33181 & 1.24745 & 0.93483 \\
\hline & & & 0.4 & 1.26857 & 1.36592 & 1.26235 & 1.03346 & 1.30895 & 1.24434 & 0.96016 \\
\hline & & & 0.6 & 1.2574 & 1.32774 & 1.25323 & 1.06756 & 1.28526 & 1.24124 & 0.99595 \\
\hline & & & 1 & 1.23507 & 1.23507 & 1.23507 & 1.23507 & 1.23507 & 1.23507 & 1.23507 \\
\hline & \multirow[t]{4}{*}{ S } & 0.9943 & 0.2 & 0.99207 & 0.9922 & 0.99206 & 0.99155 & 0.99216 & 0.99201 & 0.99147 \\
\hline & & & 0.4 & 0.99263 & 0.99272 & 0.99262 & 0.99223 & 0.99269 & 0.99258 & 0.99217 \\
\hline & & & 0.6 & 0.99319 & 0.99325 & 0.99318 & 0.99292 & 0.99323 & 0.99316 & 0.99288 \\
\hline & & & 1 & 0.9943 & 0.9943 & 0.9943 & 0.9943 & 0.9943 & 0.9943 & 0.9943 \\
\hline & \multirow[t]{4}{*}{$\mathrm{h}$} & 5.79924 & 0.2 & 5.99682 & 9.29689 & 5.82733 & 3.16766 & 6.23369 & 5.84977 & 4.41527 \\
\hline & & & 0.4 & 5.94743 & 9.201 & 5.82029 & 3.19642 & 6.13078 & 5.83709 & 4.53434 \\
\hline & & & 0.6 & 5.89803 & 9.06585 & 5.81326 & 3.23697 & 6.0243 & 5.82444 & 4.70226 \\
\hline & & & 1 & 5.79924 & 5.79924 & 5.79924 & 5.79924 & 5.79924 & 5.79924 & 5.79924 \\
\hline & \multirow[t]{4}{*}{$\mathrm{CV}$} & 0.64555 & 0.2 & 0.64639 & 0.65131 & 0.64601 & 0.63313 & 0.65125 & 0.64856 & 0.64722 \\
\hline & & & 0.4 & 0.64618 & 0.64988 & 0.6459 & 0.6361 & 0.65084 & 0.64706 & 0.64703 \\
\hline & & & 0.6 & 0.64597 & 0.64844 & 0.64578 & 0.63915 & 0.64942 & 0.64656 & 0.64674 \\
\hline & & & 1 & 0.64555 & 0.64555 & 0.64555 & 0.64555 & 0.64555 & 0.64555 & 0.64555 \\
\hline \multirow{20}{*}{ Case VI } & \multirow[t]{4}{*}{$\gamma$} & 0.5045 & 0.2 & 0.43883 & 0.44881 & 0.43799 & 0.4051 & 0.45353 & 0.42866 & 0.33399 \\
\hline & & & 0.4 & 0.45525 & 0.46363 & 0.45451 & 0.42223 & 0.46733 & 0.4462 & 0.34355 \\
\hline & & & 0.6 & 0.47167 & 0.47782 & 0.47111 & 0.44293 & 0.48037 & 0.46465 & 0.35738 \\
\hline & & & 1 & 0.5045 & 0.5045 & 0.5045 & 0.5045 & 0.5045 & 0.5045 & 0.5045 \\
\hline & \multirow[t]{4}{*}{$\theta$} & 1.3311 & 0.2 & 1.17615 & 1.26205 & 1.16917 & 0.90777 & 1.22187 & 1.14439 & 0.69244 \\
\hline & & & 0.4 & 1.21489 & 1.2807 & 1.20904 & 0.93606 & 1.25099 & 1.18782 & 0.71261 \\
\hline & & & 0.6 & 1.25362 & 1.29836 & 1.24931 & 0.97565 & 1.27882 & 1.23334 & 0.74203 \\
\hline & & & 1 & 1.3311 & 1.3311 & 1.3311 & 1.3311 & 1.3311 & 1.3311 & 1.3311 \\
\hline & \multirow[t]{4}{*}{$S$} & 0.9953 & 0.2 & 0.98998 & 0.99019 & 0.98996 & 0.98906 & 0.99012 & 0.98988 & 0.98886 \\
\hline & & & 0.4 & 0.99131 & 0.99147 & 0.9913 & 0.99058 & 0.99142 & 0.99123 & 0.99043 \\
\hline & & & 0.6 & 0.99264 & 0.99276 & 0.99263 & 0.99213 & 0.99272 & 0.9925 & 0.99203 \\
\hline & & & 1 & 0.9953 & 0.9953 & 0.9953 & 0.9953 & 0.9953 & 0.9953 & 0.9953 \\
\hline & \multirow[t]{4}{*}{$\mathrm{h}$} & 6.21542 & 0.2 & 5.53755 & 7.73399 & 5.38766 & 2.3103 & 5.74646 & 5.39301 & 3.3192 \\
\hline & & & 0.4 & 5.70702 & 7.63926 & 5.5791 & 2.33907 & 5.87082 & 5.58518 & 3.41586 \\
\hline & & & 0.6 & 5.87649 & 7.50642 & 5.78017 & 2.37962 & 5.99012 & 5.78599 & 3.55676 \\
\hline & & & 1 & 6.21542 & 6.21542 & 6.21542 & 6.21542 & 6.21542 & 6.21542 & 6.21542 \\
\hline & \multirow[t]{4}{*}{$\mathrm{CV}$} & 0.62633 & 0.2 & 0.66976 & 0.67603 & 0.66928 & 0.65415 & 0.67569 & 0.66638 & 0.65706 \\
\hline & & & 0.4 & 0.6589 & 0.66428 & 0.6585 & 0.64644 & 0.66403 & 0.65608 & 0.63353 \\
\hline & & & 0.6 & 0.64804 & 0.65211 & 0.64775 & 0.63928 & 0.65195 & 0.64597 & 0.62994 \\
\hline & & & 1 & 0.62633 & 0.62633 & 0.62633 & 0.62633 & 0.62633 & 0.62633 & 0.62633 \\
\hline
\end{tabular}

Obviously from Table (4) when $\omega$ goes to one all results of Bayes estimates under BSE, BLINEX and BGE loss functions for $\theta, \gamma, \boldsymbol{S}(\mathrm{t}), \mathrm{h}(\mathrm{t})$ and $\mathrm{CV}$ are closed to corresponding ML estimates and equal to ML estimates when $\omega=1$. If the shape parameter (a) increase the value of $\theta, \gamma, s(t)$, $\mathrm{h}(\mathrm{t})$ and $\mathrm{CV}$ are decreased in BLINEX and BGE loss functions. Obviously from Table (4), the Bayes estimates under BLINEX loss function is approximately the Bayes estimates under BSE loss function and there for almost symmetric for $\mathrm{a}=\mathbf{0 . 2 5}$. 


\section{7 - CONCLUSION}

In this paper, we considered the Bayes estimation of the unknown parameters of the exponentiated gamma distribution when the data is collected under the unified hybrid censored data. The MLEs and the CIs based on the observed Fisher information matrix have been obtained. Under balanced loss functions we can obtain Bayes estimate so, we can using MCMC technique to computing the Bayes estimation under three different balanced losses functions. We have applied the developed techniques on a real data set to demonstrate how the proposed method can be used in practice.

\section{REFERENCES}

[1] Gupta, R.C., Gupta, P.L., and Gupta, R.D. (1998). Modeling failure time databy Lehman alternatives. journal Communications in Statistics -Theory and Methods, 27, 887-904.

[2] Bakoban, R.A. (2010). Study on mixture of exponential and exponentiated gamma distributions. Advances and Applications in Statistical Sciences, 2, 101-127.

[3] Shawky, A.I. and Bakoban, R.A. (2012). Exponentiated gamma distribution different methods of estimations. Journal of Applied Mathematics, 23, 284-296.

[4] Epstein, B. (1954). Truncated life-test in exponential case. The Annals of Mathematical Statistics, 25, 555-564.

[5] Childs, A., Chandrasekar, B., Balakrishnan, N., and Kundu, D. ( 2003). Exact likelihood inference based on Type-I and Type-II hybrid censored samples from the exponential distribution. Annals of the Institute of Statistical Mathematics, 55, 319-330.

[6] Chandrasekar, B., Childs, A., and Balakrishnan, N. ( 2004). Exact likelihood inference for the exponential distribution under generalized Type-I and Type-II hybrid censoring. Naval Research Logistic, 51, 994-1000.

[7] Saieed F. Ateya. (2015). Estimation under Inverse Weibull Distribution based on Balakrishnanâ $€^{\mathrm{TM}_{\mathrm{S}}}$ Unified Hybrid Censored Scheme. Communications in Statistics - Simulation and Computation,1532-4141 (Online).

[8] Balakrishnan N, Rasouli A, Sanjari Farsipour N.(2008) Exact likelihood inference based on an unified hybrid censored sample from the exponential distribution. Journal of Statistical Computation and Simulation.78, 475-788.

[9] Jozani, M.J., Marchand, E., and Parsian, A. (2012). Bayes and robust Bayesian estimation under a general class of balanced loss functions. Statistical Papers, 53, 51-60.

[10] Zellner, A. (1986). Bayesian estimation and prediction using asymmetric loss functions. Journal of the American Statistical Association, 81, 446-545.

[11] Chen, M.H. and Shao, Q.M. (1999). Monte Carlo estimation of Bayesian credible and HPD intervals. Journal of Computational and Graphical Statistics, 8, 69-92.

[12] Metropolis, N., Rosenbluth, A.W., Rosenbluth, M.N., Teller. A.H., and Teller, E. (1953). Equations of state calculations by fast computing machines. Journal of Chemical and Physics, 21, 1087-1091.

[13] Kumar, S. and Umesh, (2015). Bayesian estimation for exponentiated gamma distribution under Progressive Type-II Censoring using different approximation techniques. Journal of Data Science, 13, 551-568. 


\section{الملخص العربي}

في هذا المقال تم در اسة تقدير المعلمات المجهوله لتوزيع جاما الاسي باستخدام هجين موحد مـن البيانـات المر اقبه بالاضـافه الي حساب قيم داله البقاء ومعدل الفشل ومعامـل الاختلاف ـ وتـم در اسـة طريـق القيمسه العليـا و التقدير البايزي لهذا التوزيع و لايجاد التقدير البايزي للمعلمـات سـوف نسـتخدم طريقه سلسـله مـاركوف مـونتي كارلو وتم حساب فترات الثقه للمعلمات المجهوله ودالة البقاء علي قيد الحياه ومعدل الفثـل ومعامـل الاختلاف . تستند جميع النتائج التي تـم الحصـول عليهـا إلى الخسـارة التربيعيـة المتوازنـة ، والخسـارة الأسـية المتوازنـة ، ووظائف فقدان الانتروبيا العامة المنو ازنـة. في نهايـة المقـال ، اسـتخدمنا بيانـات حقيقيـة لتحديد كيفيـة اسـتخدام طريقة التقدير في الممارسة العملية. 